\section{FIRST INTERNATIONAL CONFERENCE OF PRINTING RESEARCH INSTITUTES}

$I^{\mathrm{T}}$

is no easy task, in science as in politics, to convene an international meeting, but in science the results are invariably worth while; and the first International Conference of Printing Research Institutes. proved no exception to this rule and well justified the effort put into the general arrangements for receiving delegates from France, Denmark, Holland, Sweden and Western Germany for the three-day period of the Conference, held during November 26-28. Such a conference has been long overdue, and it may be said that success attended it, the general desire being to hold a second conference, in early 1953, in Stockholm by courtesy of the Grafiska Forskningslaboratoriet, when it is proposed to discuss "The Printing Properties of Paper".

As is usual on such occasions, considerable benefit was obtained from personal contact with workers in similar fields, and it was possible, Conference agenda apart, for research workers to get to grips jointly on their different problems-always preferable to corresponding with just a name.

The first day of the Conference was devoted to a tour of the laboratories of the Printing, Packaging and Allied Trades Research Association (Patra) and to a general discussion on the organization of printing research institutes, to which contributions were made by G. L. Riddell (Patra), G. E. Carlsson (Sweden), J. F. Monroy (Holland), E. E. Andersen (Denmark), A. Bargilliat (France) and J. Albrecht (Western Germany). There appeared to be a surprising degree of uniformity of organization and programmes, coupled with a not surprising shortage of both finance and scientific man-power.

The second day, given over to papers and discussion of the physics of letterpress printing, was opened by G. E. Carlsson and L. Pihl (Sweden), who reported that preliminary results of their work indicated that the dynamic pressure generated on printing elements is mainly determined by their size and distance from other elements. The pressure generated by penetration of printing elements into the elastic cylinder covering is greater for a small than a large element, the pressure increasing os a linear function of the speed of printing. Lubrication by the printing ink decreases the pressure.

R. G. Croney (Patra) reported on the mean pressure generated on printing elements of different sizes and shapes when they penetrate the elastic cylinder covering of the printing machine. This pressure varies inversely with the radius of the printing element, because the volume of the cylinder covering compressed by the penetrating element extends beyond the perimeter of the element and is proportionately greater for small elements than for large. The occurrence of high pressures at the edges of printing elements can be predicted mathematically, and demonstrated by making prints from sensitive carbon paper or by the rounding of the edges of type and other printing elements during use. The fidelity of repro. duction without 'make-ready' from soft rubber and thermoplastic printing plates has been shown to give a better correlation with dynamic resilience than with measurements of static hardness.

'The application of the work to 'make-ready' (the rough equalization of pressures by hand manipulation), which may render half the useful life of a commercial printing machine unproductive, was discussed. Describing the uses of limit gauges in pre-makeready, J. F. Monroy (Holland) demonstrated a newly designed gauge for indicating the correct thickness of the cylinder packing, the instrument being in two halves and fitted with a dial to record the relative displacement of the two sections when the gauge passes through tho printing machine. Monroy also described the method developed in Holland for determining the best screen-ruling for half-tone plates. The screen depends on the surface characteristics of the paper, the fineness of grinding of the printing ink, the ink film-thickness and the printing density required. The screen to be used for a given set of printing conditions is determined by using a controlled proof-printing technique. An empirical formula relating the screen ruling with the density of the print at a given ink film thickness has been derived.

On the final day of the Conference, which was devoted to ink drying, R. R. Coupe and A. H. Smith (Patra) dealt with the penetration of oil from ink into paper, the final depth of penetration being measured by two methods, namely, by measuring the volume of unfilled voids in the paper by absoŕrbing a liquid such as oleic acid, extracting and analysing, or by cutting a thin section of the print at right angles to the plane of the paper and measuring the depth of penetration by means of a microscope. In this latter method the paper is embedded in polyethylene and the section taken with a microtome and stained with iodine. Results indicate that the distance of penetration into the paper is linearly related to the thickness of the ink film applied, and it has been shown that the separation of varnish from the ink after printing is determined to a large extent by the capillary structure of the paper on which the print is made. Reflectance methods for measuring the rate of penetration of oil from inks into paper were also outlined.

G. F. Carlsson and L. Pihl reported a statistical analysis of their data on the height of rise of viscous oils up strips of paper and the time taken for oil to penetrate the paper in a direction at right angles to the surface (oil flotation number). There is a linear relationship between the reciprocal of the oil flotation number and the square of the height of rise, and the results indicate large differences in the main capillary pore sizes in the two paper directions.

Carlsson and Pihl also reported some observations made on the factors influencing the drying of lithographic printing inks. There is evidence that the water used in lithography emulsifies with the ink, and certain additions commonly used in the damping water, notably phosphates, react with the metallic soap driers in the inks. A new drier based mainly on calcium perborate was described.

The final papers were read by R. R. Coupe (Patra) on the inhibition of drying of lithographic varnishes by acid and salt solutions and on the influence of the paper on drying. The mechanism of inhibition is the extraction of the drier metal from the varnish by the aqueous salt solution, and this is highly dependent on the anion present and on the $p \mathrm{H}$. Phosphates, sulphates, citrates and low $p \mathrm{H}$ values favour inactivation of the drier metals. Nitrates, chlorides and chromates have little effect.

Paper can slow down the drying of varmish containing metal soaps, and this is probably associated with the adsorption of the drier metel on the cellulose fibres. If linseed oil containing cobalt soaps is allowed 
to rise up a strip of paper and the paper afterwards developed with Nitroso- $R$ salt, it can be shown that cobalt is adsorbed on the lower part of the strip, the oil being denuded of drier. Acid papers adsorb the cobalt more strongly. The adsorption is irreversible and probably involves the hydrolysis of the cobalt soap or an ion exchange process between the soap and the cellulose. The rate of adsorption is slow, and the amount adsorbed at any given time is proportional to the square root of the time.

Arrangements are being made for the publication in full of the papers read and the ensuing discussions.

G. L. RIDDELL

\section{CORROSION OF BURIED METALS}

A

SYMPOSIUM on the corrosion of buried metals was held jointly by the Iron and Steel Institute, the British Iron and Steel Research Association and the Corrosion Group of the Society of Chemical Industry in London on December 12. Sir Charles Goodeve was in the chair, and about three hundred people attended. Preprints of the papers under discussion were circulated before the meeting.

In his opening remarks, Sir Charles Goodeve said that modern communities are dependent on a number of services, of which the chief are water, gas, electricity and sewage, and the corrosion of underground pipelines or cables conveying these is a problem of great magnitude. He referred to the report of the Ministry of Health Departmental Committee on the Deteriora. tion of Cast Iron and Spun Iron Pipes published in 1950. This report stressed the need for further research, and the work had been entrusted to the British Iron and Steel Research Association's SubCommittee on the Corrosion of Buried Metals formed in March 1950. Represented on this Sub-Committee were manufacturers and users of ferrous and nonferrous materials, gas and water engineers and others, so that a very satisfactory representation and co-ordination of the interests concerned had been achieved. One of the earliest actions of the Sub-Committee was to make plans for the present symposium.

In the first session the papers discussed were "Tests on the Corrosion of Buried Iron and Steel Pipes" by J. C. Hudson and G. P. Acock, and "Investigations on Underground Corrosion" by K. R. Butlin, W. H. J. Vernon and L. C. Whiskin. In introducing the first paper, Dr. Hudson gave a brief survey of the events leading to the research, and $\mathrm{Mr}$. Acock described the interim results contained in the paper. The second paper was introduced by Dr. Vernon.

Dr. W. F. Higgins, opering the discussion, questioned the value of tests using short lengths of pipe, and pointed out that variations in the composition of the soil along the length of a pipe could, by a concentration-cell effect, lead to corrosion at certain places. Such effects were not reproduced in the tests described, which could not, therefore, purport to indicate the behaviour of pipe-lines. Mr. W. G. Waite supported this contention and mentioned a number of other ways in which the test conditions were different from those of practice. He felt that additional useful information would have been provided by measurements of the loss of mechanical properties of the materials buried, and determinations of the con- ductivities of soil waters. Mr. N. J. Pugh was also doubtful about the value of tests on short lengths. He mentioned several factors occurring in practice which could affect the course of corrosion, particularly the setting up of internal stresses by pressure fluctuations in water mains. Sir Charles Goodeve afterwards commented on these criticisms of the use of small specimens and pointed out that similar problems arise in many branches of scientific work. It is a fact, he said, that the accuracy of measurement falls off as the scale of the experiment increases, until on the full scale the accuracy is usually too low to give useful results owing to the presence of uncontrolled variables. Furthermore, the cost of experiments rises sharply as the scale increases. A compromise is desirable where accuracy of measurement, correspondence to practical conditions and cost are all at reasonable levels.

A number of speakers discussed the merits and disadvantages of various protective coatings or schemes. Mr. Hussey pointed out that certain soils are not corrosive, as shown by the condition of excavated museum specimens, and thought that certain elay-chalk mixtures might be used to give protection. Mr. Warner described how 6 in. of puddled clay around buried tanks used for storing petroleum products had kept the tanks in relatively good condition for more than sixty years, connecting pipe-lines having been much more severely corroded. Mr. E. W. Rawlings said that latex cement, which can be applied by spraying, has been successfully used.

Dr. F. Wormwell gave some details of work in progress at the Chemical Research Laboratory, Teddington. Electrochemical measurements are being made to throw more light on the mechanism of microbiological corrosion. It has been found that this type of attack can be prevented by cathodic protection. Earlier Mr. Waite had expressed the view that perhaps too much emphasis had recently been given to the part played by bacteria in corrosion, and in the course of his reply to the discussion Dr. Vernon said that, he and his colleagues have taken every opportunity of pointing out that microbiological corrosion is not basically different from electrochemical corrosion, of which it is merely a special type. He stressed that, contrary to the views expressed by one or two speakers, a noteworthy feature of soil corrosion research is the close co-operation that has been established between research workers and users. Mr. L. C. Whiskin, chairman of the Sub-Committee on Corrosion of Buried Metals, referred briefly to the current activities of the Sub-Committee.

In the second session the two papers discussed were "Cathodic Protection" by K. A. Spencer and "Cathodic Protection of Buried Metal Structures" by R. de Brouwer. Mr. Spencer introduced both his own paper and that by M. de Brouwer, who was unfortunately prevented from attending. During the course of his introduction, Mr. Spencer showed a short film on the laying of an oil pipe-line in Scotland, illustrating the installation of magnesium anodes.

Several speakers stressed the low cost of cathodic protection and its high efficiency in preventing corrosion. Mr. C. W. Marshall mentioned successful applications of the method in Belgium and Holland, and Dr. A. J. Maurin described its application in France. $\mathrm{He}$ distinguished between specific aggressivity and apparent aggressivity over the length of a pipe-line, and said that nomograms have been constructed for calculating specific aggressivity from certain soil 